\title{
FOCUS ON QUALITY
}

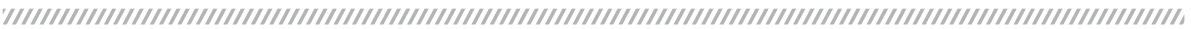

Dear Reader,

Within a span of seven days last month, market leader Maruti Suzuki India Ltd initiated two recalls involving over 75,000 Baleno hatchbacks, close to 2,000 DZire compact sedans and an unspecified number of S-Cross crossovers. MSIL, of course, isn't the only one. Automobile recalls have become very prevalent in the past few years, with India alone accounting for an estimated $2.24 \mathrm{mn}$ vehicle recalls between July 2012 and May 2016, an analysis by a leading business daily stated.

Does this point towards a decline in automotive reliability and safety? Does this mean the vehicles produced today are of poor quality as against vehicles of the past? Not necessarily. While some automakers have blamed quality issues at smaller component vendors, the most significant story emerging in recent times is that of Japanese supplier, Takata. As per one estimate, nearly $78 \mathrm{mn}$ defective, shrapnel-shooting Takata airbag inflators will need replacement through 2019.

Until some time back, most of the vehicles recalled globally used to be older models with newly discovered problems. But that seems to be changing. Popular new products from Honda, Ford, Volkswagen, MSIL, HMSI and Yamaha, among others, have been recalled in recent times. Honda has been the worst affected with over 5.13 lakh recalls in the last four years, primarily due to issues with airbags sourced from Takata.

Experts point out that the increasing use of common parts, complex architectures, and heavy dependence on electronics \& software, are some of the key reasons leading to a spurt in vehicle recalls. Overall, the large number of defective systems and parts getting into vehicles highlight one serious concern - that of inadequate quality assurance.

Many of our readers, who attended the annual ACMA convention in 2015, would recall what Osamu Suzuki, Chairman, Suzuki Motor Corporation had said - global recall of more than 1 $\mathrm{mn}$ vehicles has put the focus on quality. He said it is quality alone that is key to success. He urged the industry to look at the 'Make in India' campaign in a larger context to include 'Quality in India'.

There couldn't be a sounder advice to the Indian industry than that.

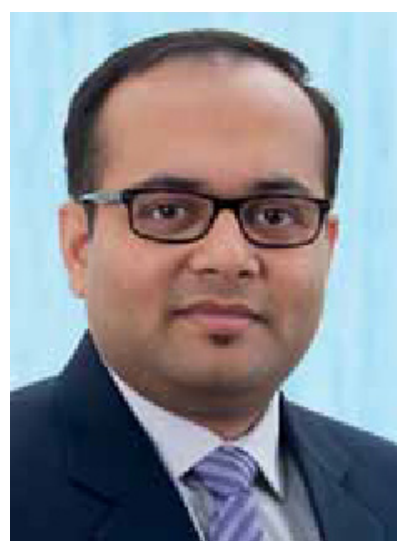

autotechreview.com

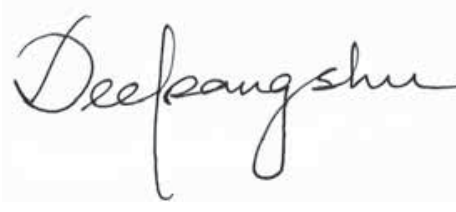

DEEPANGSHU DEV SARMAH

Editor-in-Chief

New Delhi, June 2016 